\title{
Expansion of Earthquake (EQ) time Equatorial Anomaly: an index of precursor as seen in major Nepal EQ of April 2015
}

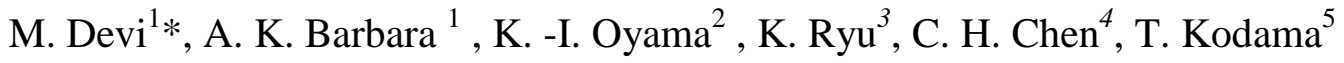 \\ ${ }^{1}$ Deparment of Physics, Gauhati University, Guwahati, Assam, India \\ ${ }^{2}$ International Center for Space Weather Study and Education, Kyushu University, Fukuoka, Japan \\ ${ }^{5}$ Satellite Technology Research Center, Korean Advanced Institute of Science and Technology(KAIST), \\ Daejeon, Korea \\ ${ }^{4}$ National Cheng-Kung University, Tainan, Taiwan \\ ${ }^{5}$ Japan Aerospace Exploration Agency, Tsukuba, Japan \\ *Email: md555gu@gmail.com
}

\begin{abstract}
The application of Electromagnetic methods in the research field of EQ precursor study with aims of identifying signature of an impending EQ and its epicenter, needs new approaches and techniques, because even with the available volume of work and reports on these aspects, the problem remains still a challenging one. The paper addresses such aspects in case of the Nepal EQ of April , 2015 (epicentre at $28.266 \mathrm{~N}$ and $84.463 \mathrm{E}$ ), of magnitude $\mathrm{M}=7.9$, by examining through analysis of global Total Electron content (TEC) data for detection of precursive anomaly signature in the Earthquake time Equatorial Anomaly (EEA), a feature observed to develop at the equator and in the longitude sector of the epicentre. Significant that, along with the EEA, a remarkable increase in TEC develops days before the impending earthquake persisting even to late night hours at the epicentre, a location just outside the normal equatorial anomaly belt . This feature is associated with the expansion of Earthquake time Equatorial Anomaly Crest (we call EEAC). The explanations of such phenomena are sought in pumping process of ionization density mainly by ExB drift, where $\mathrm{E}$ is the earthquake modified electric field. Possible additional sources working for growth \& development of EEA and EEAC are also suggested.
\end{abstract}

Key Words: Earthquake; Global TEC; Appleton Anomaly Crest; Nepal EQ; Electric field 


\section{Introduction}

A significant number of works related to earthquake (EQ) time ionospheric study, show possible modifications of atmospheric parameters prior to and during an earthquake event [Davies and Baker 1965; Calais and Minster , 1995; Ruzhin and Depueva, 1996]. The magnitude of such changes may vary with latitude, longitude of the epicentre position as well as on the solar geomagnetic status of the earthquake time [Depueva et al., 2007; Devi et al., 2008; Oyama et al ., 2011; Devi et al., 2011(a); Liu et al. , 2013; Devi et al., 2014; Smirnov et al., 2015 ]. Equatorial anomaly factor takes a key role in such changes specially when the epicentre lies near to the equator and at low latitudes [Depueva and Ratanova, 2001; Devi et al., 2001; Devi et al., 2004; Devi et al., 2011(b)]. In case of an EQ with epicentre at mid latitude, the equatorial anomaly effect may not be very effective but there are still evidences of growth of Earthquake time Equatorial Anomaly (EEA), significantly at the longitude zone of a mid- latitude EQ epicentre [Devi et al., 2012; Devi et al., 2013; Ryu et al., 2014; Ryu et al., 2016]. Such modifications of anomaly prior to mid latitude EQs are also shown through model computation by Karpov et al., [2013]. However, in such cases, the sources and physics involved in one event to the other being highly variable, the EQ precursor study is still a challenging problem especially in anomaly crest locations.

The Nepal EQ of M = 7.9 that struck $77 \mathrm{~km}$ northwest of Nepal's capital Kathmandu at 0611 hrs GMT on 25 April 2015, with epicentre at $28.266^{\circ} \mathrm{N}$ and $84.463^{\circ} \mathrm{E}$, a location just above the normal equatorial anomaly crest, is expected to exhibit prominently the effects of any change in the physical and dynamical status of the equatorial anomaly caused by a massive earthquake and therefore possible prediction parameters for identifying the epicentre would be sharply on focus. With this background and aims, Global Total Electron Content (TEC) data are examined to look for growth and development of EQ time equatorial anomaly, a feature associated by Devi et al., [2012; 2013] in prediction of Japan EQ of March 2011. 


\section{Analysis and result.}

\subsection{Global TEC features prior to Nepal EQ of April 25}

The Global TEC maps are analyzed on routine basis and appearance of anomalous features specially growth of Earthquake time Equatorial Anomaly (EEA) is examined as a possible prelude to an EQ. The analysis shows that Normal Equatorial Anomaly (NEA) (i.e., Appleton Anomaly) develops during daytime, and its position shifts from east to west longitude zone as day advances. As an example, one can note from Figure 1(a), the presence of NEA in $90^{\circ} \mathrm{E}-100^{\circ} \mathrm{E}$ longitude zone at 6 UT (i.e. local noon/post noon hours) and at $11 \mathrm{UT}$ (local noon/post noon hours) in the $30^{\circ} \mathrm{E}-40^{\circ} \mathrm{E}$ longitude sector (Figure $1 \mathrm{~b}$ ) .

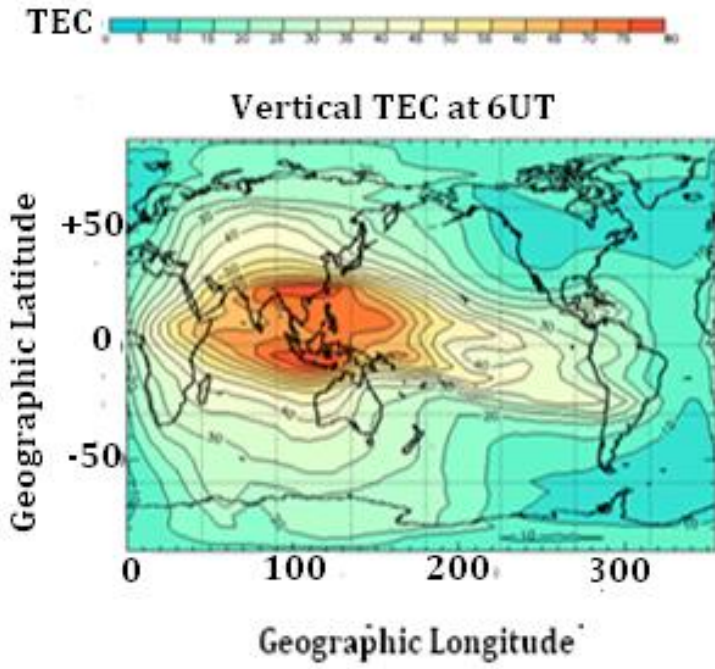

(a)

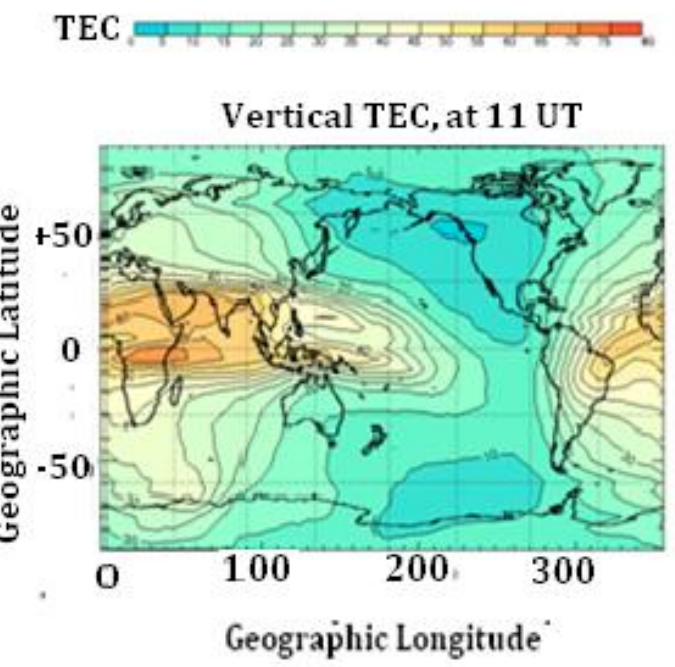

(b)

Figure 1. Displays development of Normal Equatorial Anomaly (a) around $90^{\circ} \mathrm{E}-100{ }^{\circ} \mathrm{E}$ longitude at $6 \mathrm{UT}$ (during local day hours and (b) at $11 \mathrm{UT}$ ( local day hours) in \& around $20^{\circ} \mathrm{E}$ to $30^{\circ} \mathrm{E}$ longitude , weeks before the massive Nepal EQ of April 2015.

But from early part of April-2015, an anomalous TEC zone starts appearing at $90^{\circ} \mathrm{E}-100^{\circ} \mathrm{E}$ longitude more significantly at 12 UT i.e., during the night sector and we present in Figure 2(a) formation of such an intense TEC contour on April $17^{\text {th }}$ in this longitude sector and $10^{\circ} \mathrm{S}$ to $15^{\circ} \mathrm{S}$ latitude zone. The growth of such strong density zone around the equatorial region significantly at 
the epicentre longitude was also found to appear prior to the massive Japan EQ of March 2011 .This observation was noted and reported by Devi et al., [2012; 2013] and this phenomenon is termed by them as Earthquake time Equatorial Anomaly (EEA). The EEA feature as shown in Figure 2 (a) for April 17 had grown stronger on April 18 [(Figure 2(b)] and along with this development, also an intense density zone appeared during afternoon to evening hours at about $25^{\circ} \mathrm{N}$ latitude and $80^{\circ} \mathrm{E}-90^{\circ} \mathrm{E}$ longitude, just above the normal equatorial anomaly crest location. This strong density as it appears at the anomaly crest zone synchronously with the development of Earthquake time Equatorial anomaly, we call this formation as Earthquake time Equatorial Anomaly Crest (EEAC).

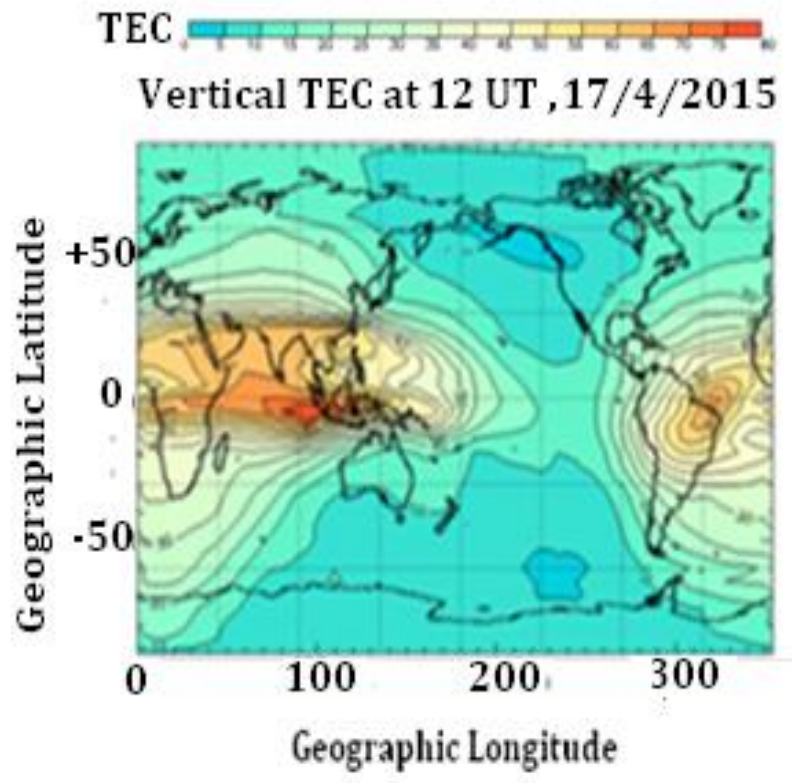

(a)

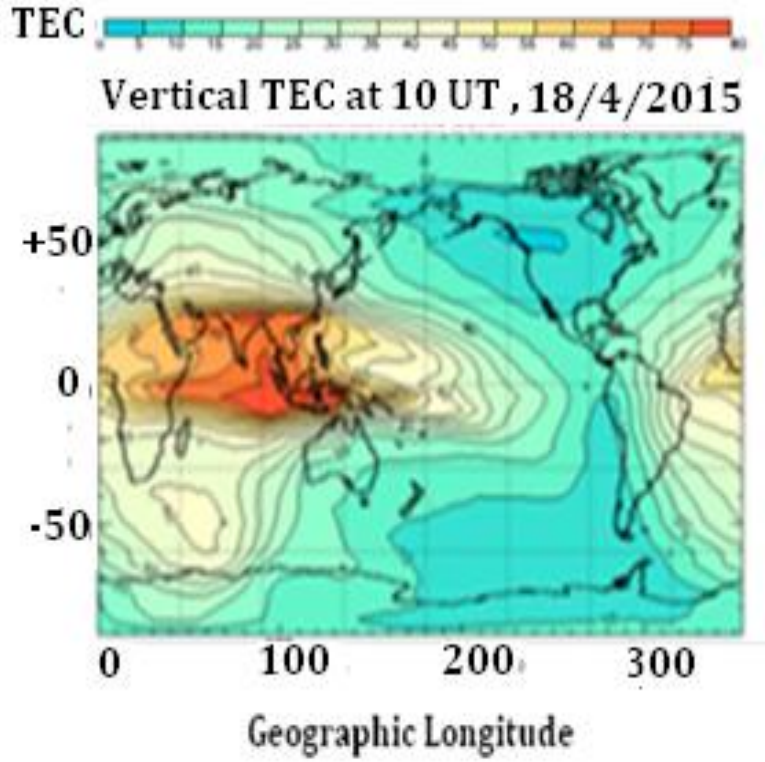

(b) 


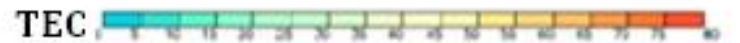

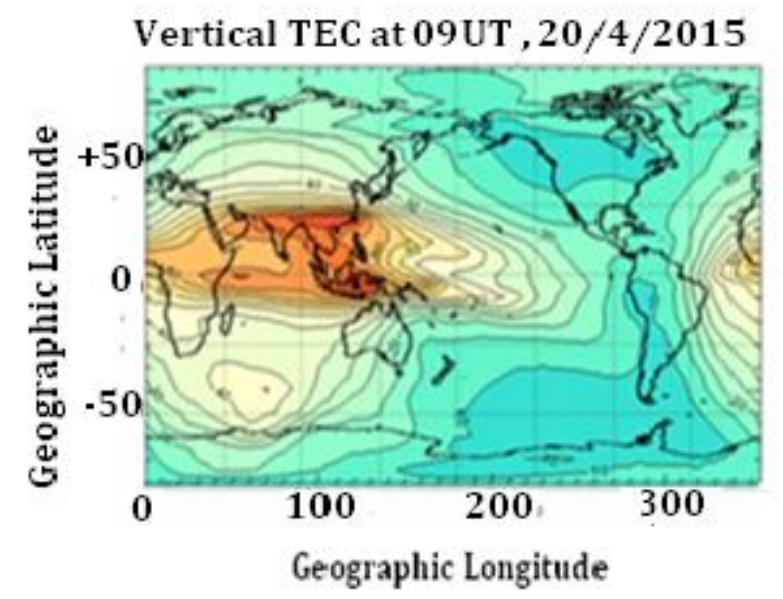

(c)

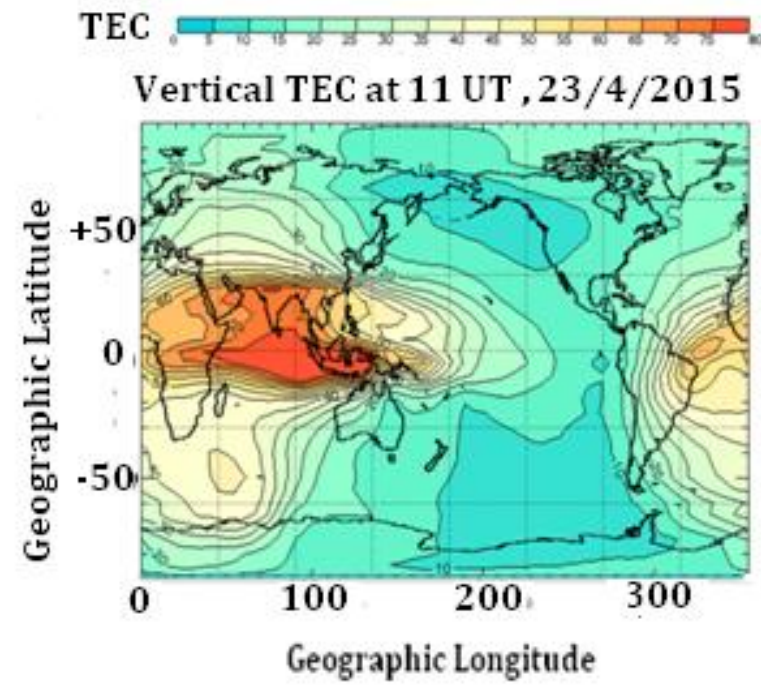

(e)

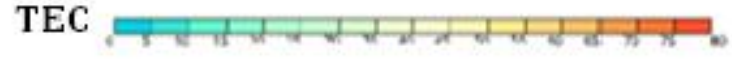

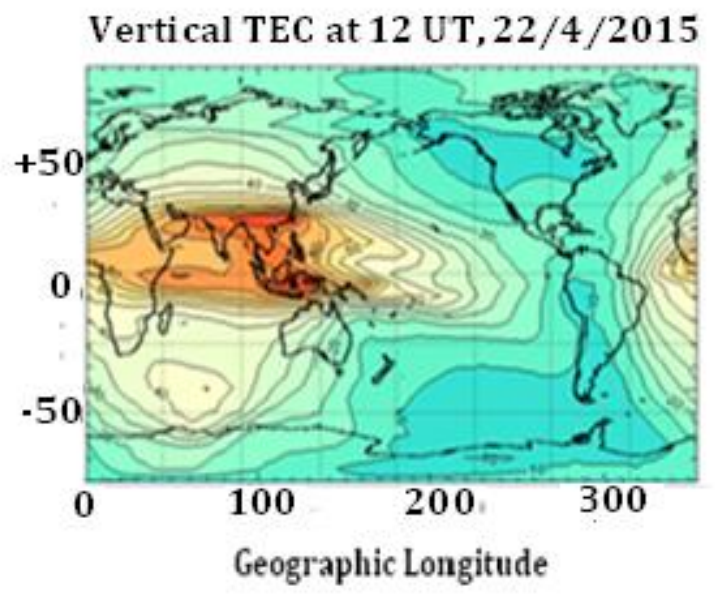

(d)
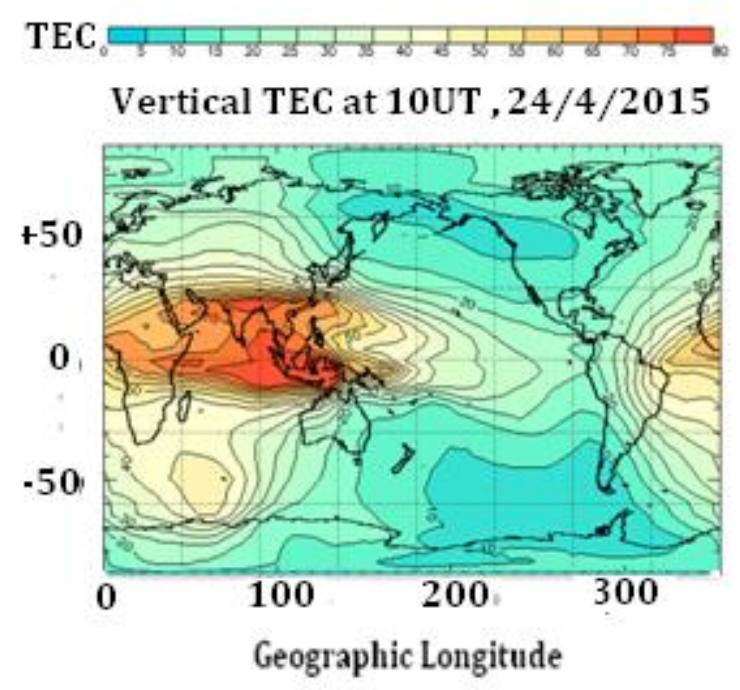

(f) 


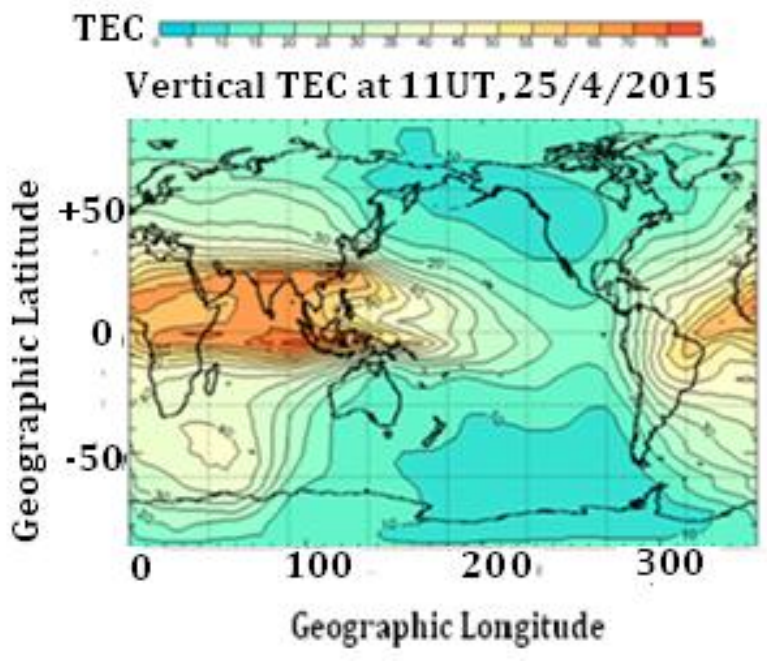

(g)

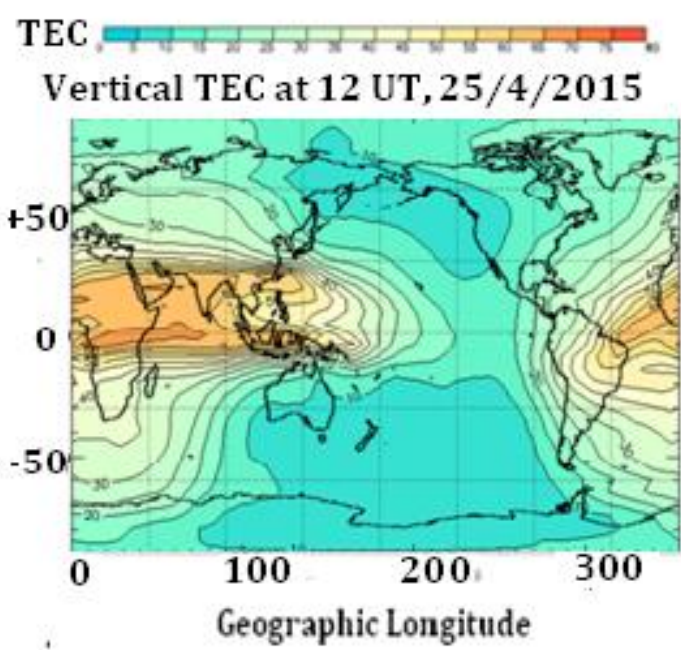

(h)

Figure 2 . Dispalys develoment of (a) EEA on April 17 , i.e., 9 days prior to the massive Nepal EQ and (b-g) EEA and EEAC features from April 18 to 24 , just prior to the occirrence of the earthquke. . The dissipation of the EEA and EEAC are seen on April 25 (h).

It is also observed that strength of EEA becomes so strong in some of the days that its effect was visible up to $10^{\circ} \mathrm{N}$ latitude [Figures 2(b), 2(e) and 2(f)]. Along with this strong EEA signature, the EEAC too appeared in the TEC maps with full strength till April $24^{\text {th }}$. The intensity of both EEA and EEAC decreases from April 25 [Figure 1(h)] and disappears after that . Based on the growth and development process of EEA and EECA from April 18 to 24, an EQ is predicated to occur on April $25^{\text {th }}$, on basis of the approach of Devi et al., [2013]. But to identify the epicene location, it is essential to estimate the magnitude of EEA and EEAC. For addressing this aspect the following procedures are adopted:

(i) The maximum latitudinal spreads of EEA and EEAC (areas where EEA and EEAC converge are examined as the first index

(ii) Longitudinal spread within the maximum latitudinal range is then defined

(iii) TEC value within the anomaly latitude-longitude zone is marked

The magnitudes of EEA and EEAC are finally determined by the following approach: 
For evaluation of EEA, the increase in TEC value within this anomaly zone (as defined in the items (i, ii and iii above), with respect to the ones prevailing in the Normal Equatorial Anomaly (NEA), is calculated. The EEAC strength is determined from the increase in TEC value within the EEAC anomaly zone (as defined in items i, ii and iii above), with respect to average value of TEC at the particular defined areas.

The EEA and EEAC strengths so determined are expressed in grades (arbitrary unit) from 0.5 to 10 , for EEA and 0.5 to 15 for EEAC, with 40 TEC $U$ as minimum value of the TEC and 80 TECU, as the maximum in the anomaly zone. The result of analysis is presented in Figure 3 where EEA and EEAC magnitudes are plotted from April 18 to April 25. One can note that both the anomalies start increasing from April 21 to reach maximum on April 24.

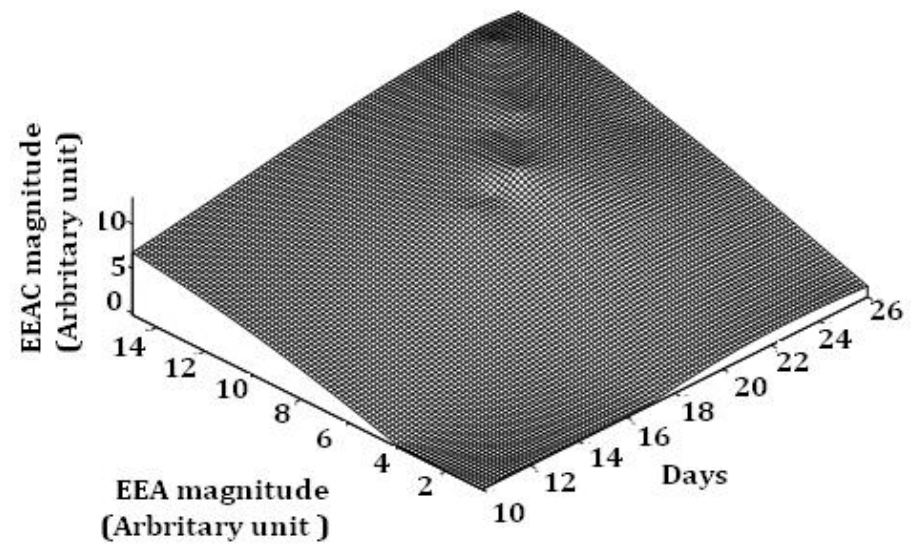

Figure 3. Displays the strength of EEA and EEAC from April 18 -24 , 2015.

The occurrence of the EEAC is a rare event, because the anomaly effect needs to be strong enough to make a high TEC zone beyond the normal anomaly crest and especially in the night sector. To identify the most likely position of the development of the EEAC, the latitudinal and longitudinal coverage of the EEAC is evaluated from the day of its appearance to its disappearance and percentage of occurrence of EEAC at a particular latitude/longitude zone is calculated from the total number of EEAC cases observed. The results as displayed in Figure 4, show that EEAC was developed within $80^{\circ} \mathrm{E}$ to $118^{\circ} \mathrm{E}$ longitude and $21^{\circ} \mathrm{N}$ to $30^{\circ} \mathrm{N}$, but the highest frequency of occurrence is at the latitude zone of $27^{\circ} \mathrm{N}-28^{\circ} \mathrm{N}$ and a longitude region spreading from 
$84^{\circ} \mathrm{E}$ to $87^{\circ} \mathrm{E}$. The analysis thus suggests a possible earthquake at $25^{\circ} \mathrm{N}-28^{\circ} \mathrm{N}$ latitude and $80^{\circ} \mathrm{E}$ $-87^{\circ} \mathrm{E}$ longitude, interestingly coinciding with the epicentre location of the Nepal EQ. Thus the approaches adopted through EEA and EEAC may well be adopted as preludes to an impending EQ.

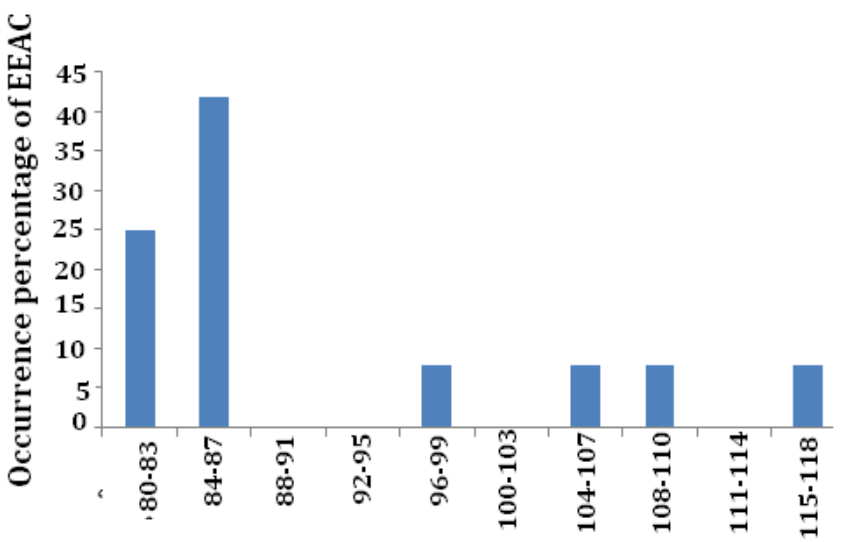

Longitude

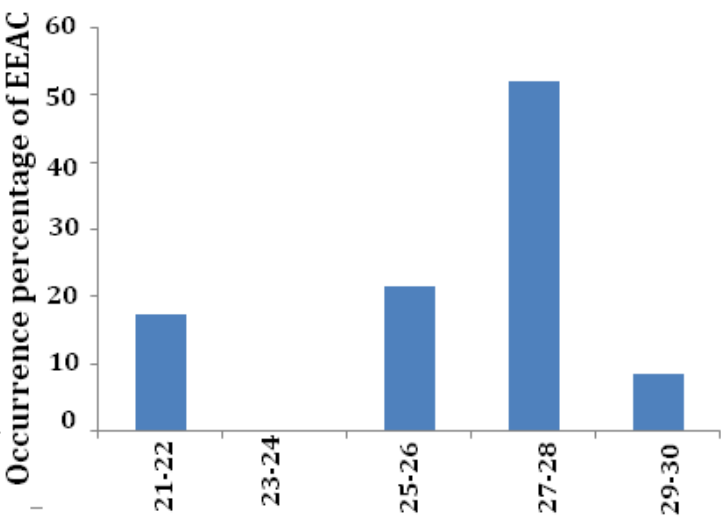

Latitude

Figure 4 . Presents latitudinal and longitudinal spreads of the EEAC. The EEAC is observed within $21^{\circ} \mathrm{N}$ to $30{ }^{\circ} \mathrm{N}$, but with highest frequency of occurrence within $27^{\circ} \mathrm{N}-28^{\circ} \mathrm{N}$. Similarly the longitudinal spread goes from $80^{\circ} \mathrm{E}$ to $118^{\circ} \mathrm{E}$ with maximum frequency of occurrence in the zone. $84^{\circ} \mathrm{E}-87^{\circ} \mathrm{E}$.

\section{Discussions}

This paper focuses a few features seen on TEC prior to the major EQ of Nepal the epicentre of which lies in the sub Himalayan region. The analysis shows that there are enhancements on TEC (i) at the equatorial anomaly $\left(-5^{\circ} \mathrm{N}\right.$ to $10^{\circ} \mathrm{N}$ Latitude) \& the epicentre longitude zones and (ii) at the anomaly crest station around the epicentre latitude /longitude of Nepal EQ. Such increase in TEC days before a seismic event at equatorial and low latitude stations can be associated with seismogenic electric field above the epicenter, which is explained by many workers [Depueva \& Ruzhin 1995; Devi et al., 2001; Devi et al 2004], through generation of a local up-drift /down drift of plasma by EXB process . Karpov et al., [2013] have shown that the electric fields of several 
$\mathrm{mV} / \mathrm{m}$ can be generated by EQ preparatory processes and such situation may result to magnification of already existing equatorial anomaly effect which can dump the density at higher latitudes beyond the normal anomaly crest zone .Devi et al., [2004] have also detected development of strong anomaly prior to the massive 8.1 earthquake over Ahmadabad $\left(23.36^{\circ} \mathrm{N}, 70.33^{\circ} \mathrm{E}\right)$ while analyzing foF2 data. This process seems to be effective in the Nepal EQ when strong anomaly effect enhances the TEC at a region just outside the Normal Equatorial Anomaly Crest. The simultaneous growth of strong EEA in the latitude zone of $-5^{\circ} \mathrm{N}$ to $10^{\circ} \mathrm{N}$ and near the epicentre longitudes suggests coupling process between development of EEA and EEAC. The intense EEA at the night sector that was observed in presence of mid latitude earthquakes from TEC global data was suggested by Devi et al., [2013] to be due to the result of westward E-field enhanced by the EQ induced processes that propagates density to lower latitudes from mid latitude epicenter through downward drift. The increase in TEC at this longitude zone is further enhanced by EM focusing effect generated at the EEA location due to the presence of the distortion of earth magnetic field in this sector [Devi et al., 2013].

But the source of development in EEA and EEAC during the day hours as seen in this EQ, (presented in Figure 5, as one of such cases) might be sought again in the EQ time E field at the epicentre or enhancement of already existing $E$ field due to modification of conductivity at the upper atmosphere through generation EQ induced waves. The additional E field will generate an extra $\mathrm{H}$ component in the near equatorial region enhancing the electrojet strength within $10^{\circ} \mathrm{N}$ latitude. This process will increase ionospheric current through the three conductivity processes and further augments the anomaly and pushes the plasma beyond the normal anomaly crest zone. The very strong anomaly noticed especially on $23^{\text {rd }}$ and $24^{\text {th }}$ April, just prior to the EQ of $25^{\text {th }}$ could be associated with such factor. 


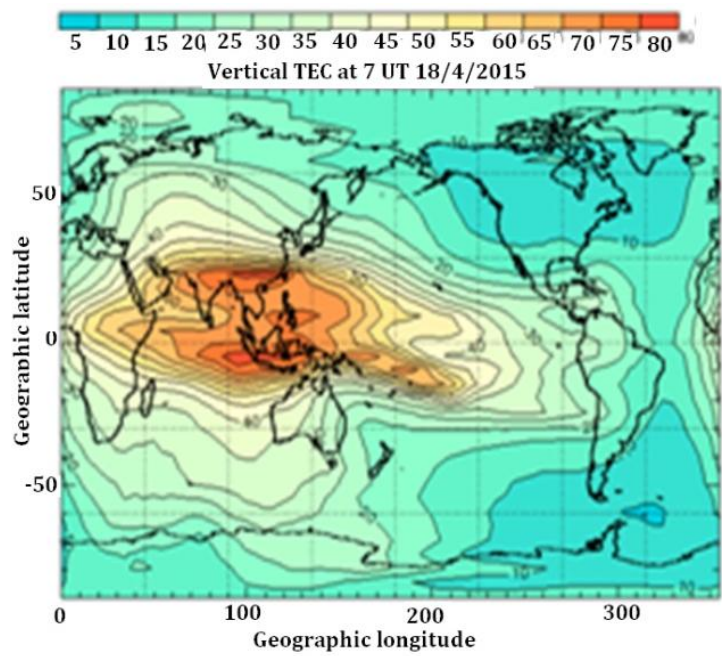

Figure 5. Dispalys develoment of day-time EEA and EEAC prior to the occrrence of Nepal EQ

One of such mechanisms of generation of current and field over a seismic area in the atmosphere ionosphere circuit is through charged aerosols emitted by the lithospheric gases which are then injected into the atmosphere. Magnitude of such current / electric filed is expected to get amplified over a thickly populated aerosol environment, when epicentre lies in such a zone as in the case of Nepal EQ. Analysis of aerosol distribution pattern from MODIS data over the epicentre region (Sub Himalayan zone), shows (Figure 6a) thick layers of aerosol during vernal Equinoxial months (i.e. March April and early May). The aerosol intensity goes down during summer with the onset of Monsoon and interesting enough to note that during Autumnal months of September and October the strength of aerosol also goes low as is seen from Figure 6(b). Under such background environment, one can expect significant contribution of aerosols in enhancement of EQ induced E field over the epicenter area of Nepal EQ that occurred in vernal Equinoxial month. This process could increase the electrojet strength augmenting the anomaly phenomenon.

There is also possibility of increasing the ionization density at the equatorial zone when the stations are connected by a fault line by emission of radon from lithosphere near to the epicenter especially in major EQ as of Nepal. Such radon emission enhances the electron density in the ionosphere and also modulates the E-field [Pulinets 2009; Freund 2009] through generation of 

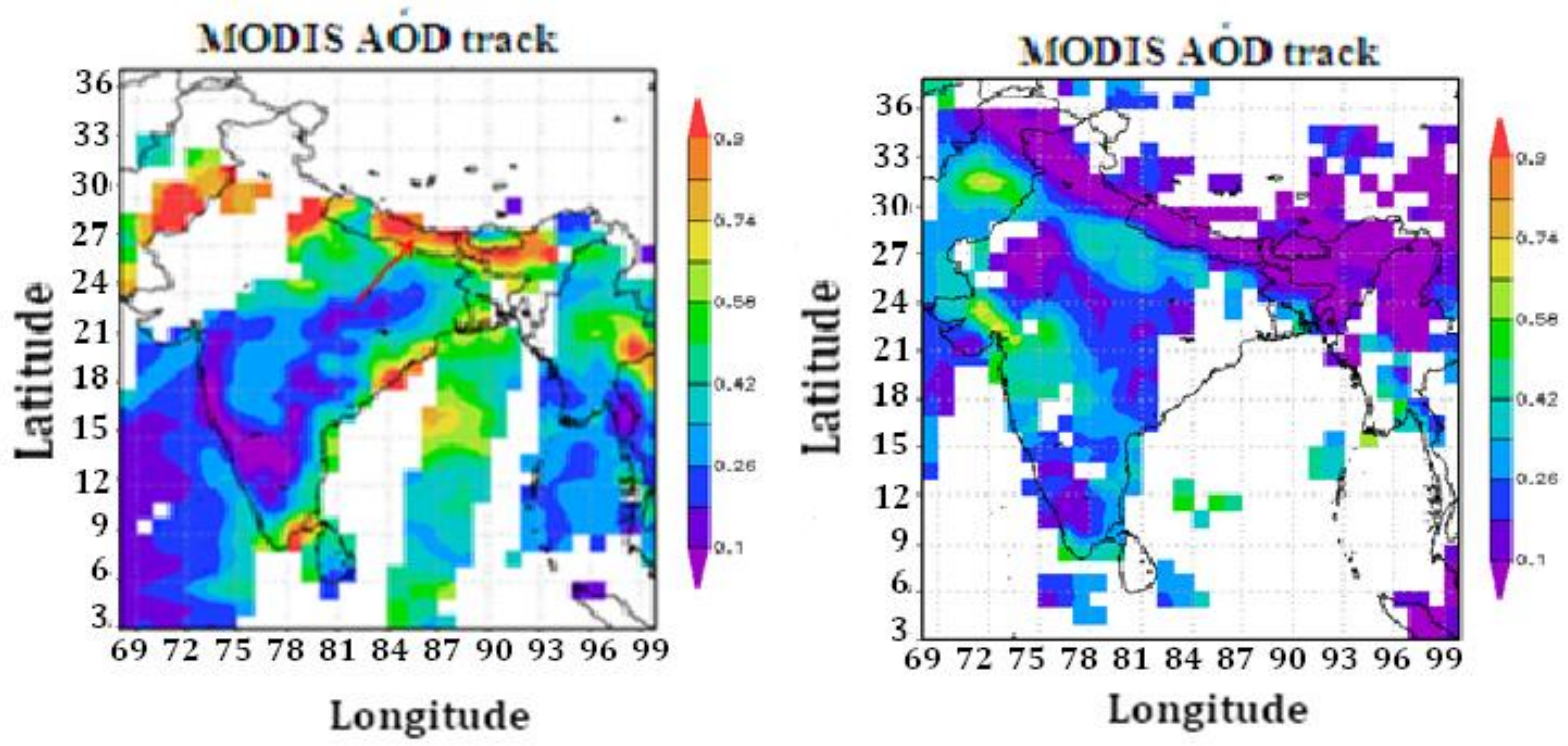

Figure 6. Dispalys AOD track received from MODIS, for (a) Vernal equnoxial months and (b) Autumnal equnoxial season . Thick aerosol layers along the Sub Himalaayn region is significant during Vernal Equnoial seasn. The colour bar shows the srength of AOD.

ionospheric current. This process could further modulate the Anomaly process and, strengthen the equatorial anomaly, as seen during April 23 and 24, 2015.

Further, it is also important to bring the conjugate status of EEAC and the EEA developed during the Nepal EQ. One may explain such association through electric current generated between the fault and ionosphere [Sorokin and Hayakawa 2013], which might drive ionospheric current both vertically and horizontally resulting to drift of anomaly both in vertical and horizontal directions along the fault lines as observed in this case .

\section{Conclusion}

The TEC global data prior to and during the very strong earthquake over Nepal show presence of Earthquake time Equatorial Anomaly (EEA), as well as growth of intense density at the epicentre location of $28{ }^{\circ} \mathrm{N}$ that lies just outside the normal Appleton anomaly crest zone suggesting widening of Earthquake time Equatorial Anomaly Crest (EEAC) . Development of EEA is observed to be so strong that intense TEC zone is detected up to $10^{\circ} \mathrm{N}$, and anomaly crest is 
expanded even during night hours. The development of EEA and EEAC are tried to explain by east ward (daytime) and westward E-field (night time) which are enhanced by the EQ preparatory processes leading to strong ionospheric current and hence electro jet strength. Contribution of EQ time emission of radon in the density enhancement may also be a factor, but justification needs further study related to measurements of radon especially around high seismic lines. These are the future courses of study.

\section{References}

Calais E and Minster, J.B., GPS detection of ionospheric perturbations following the January 171994, Northridge earthquake, Geophys. Res. Lett., Vol. 22, 1045 -1048, 1995

Davies K. and Baker D.M., Ionospheric effects observed round the time of Alaska earthquake of march 28, 1964 , Journal of Geophysical Research, Vol.70,. 2251-2263, 1965

Depueva A H. and Rotanova N., Low-latitude ionospheric disturbances associated with earthquakes. Annali di Geofisica, 44, pp. 221-228. 2001,

Depueva A H. and Ruzhin Y.Y., Seismoionospheric fountain-effect as analogue of active space experiment. Adv Space Res, 15, No-12115 - 154, 1995.

Depueva, A., Mikhailov, A., Devi, M., and Barbara, A. K. Spatial and time variations in critical frequencies of the ionospheric $\mathrm{F}$ region above the zone of equatorial earthquake preparation. Geomagnetism and Aeronomy 47,129-133, 2007.

Devi M, Barman M.K, Barbara AK, Depueva AH: Total electron content near anomaly crest as precursor of earthquake. Indian J Radio Space Phys, 30, 209-213, 2001

Devi M, Barbara AK, Depueva AH: Association of total electron content and foF2 variations with earthquake events at the anomaly crest region. Ann Geophys, 47, 83-91,2004.

Devi M, Barbara AK, Depueva AH, Depuev V. Preliminary results of TEC measurements in Guwahati, India. Adv Space Res, 42, No-4 , 753-756,2008.

Devi M, Barbara AK, Kashyap P, Depueva A, Ruzhin YY, Depuev V, Earthquake time low latitude total electron content (TEC) variations and model based pattern: identification of earthquake induced atmospheric dynamics. Adv Geosciences, 27, 69-84,2011 (a).

Devi M., Sarma A. J. D., Kalita S., Barbara A. K., Depueva A, Adoptive techniques on extraction of preseismic parameters on Total Electron Content (TEC) at anomaly crest stations using GPS data. Geomatics, Natural Hazards and Risk, doi:10.1080/19475705.2011.595831, 2011(b). 
Devi, M., Barbara, A. K: Total Electron Content and Anomalous Appearance of GPS Satellites as Pointers to Epicentre Identification of Major Japan Earthquake of 2011. Positioning, 3(2012a), pp.7-12. (http://www.SciRP.org/ journal /pos). Published Online on February 2012.

Devi M., Medhi A., Sarma A. J. D., Barbara A. K.: Growth and inhibition of equatorial anomaly prior to an earthquake (EQ): case studies with total electron content (TEC) data for major EQs of Japan 2011 and Indonesia 2012. Positioning, 4,40-252,2013

Devi Minakshi; Barbara A. K.; Oyama, Ko-Ichiro; Chen, Chia-Hung: Earthquake induced dynamics at the ionosphere in presence of magnetic storm, Advances in Space Research, Vol-53, Issue- 4, 609-618, 2014.

Freund, F.,"Stress-activated positive hole charge carriers in rocks and the generation of Pre-earthquake signals", In: M. Hayakawa (ed) Electromagnetic phenomena associated with earthquakes, Transworld Research Network, Trivandrum, pp. 41-96. 2009,

Karpov, M.I., A.A. Namgaladze, O.V. Zolotov ,Modeling of Total Electron Content disturbances caused by electric currents between the Earth and the ionosphere. Russian Journal of Physical Chemistry B, 7(5), 594598, doi:10.1134/S1990793113050187,2013.

Liu, J. Y., Chen, C. H., Tsai, H. F., A statistical study on seismoiono-spheric precursors of the total electron content associated with M 6.0earthquakes in Japan during 1998-2011. In: Hayagawa, M. (Ed.), Earth-quake Prediction Studies: Seismo Electromagnetics. TERRAPUB, Tokyo, pp. 17-30. 2013.

Pulinets ,S., "Lithosphere-atmosphere-ionosphere coupling (LAIC) model". In: Hayakawa M (ed) Electromagnetic phenomena associated with earthquakes. Transworld Research Network, Trivandrum, pp 235-253,2009.

Oyama, K. I., Kakinami Y., Liu J. Y., Abdu M. A., Cheng C. Z., J. Geophys. Res.. 116, A04319, doi:10.1029/2010JA015948, , 1-15, 2011.

Ryu, K., Lee, E., Chae, J. S., Parrot, M., Oyama, K.-I.' Multisatellite observations of an intensified equatorial ionization anomaly in relation to the northern Sumatra earthquake of March 2005. J. Geophys. Res., Vol-119,.4767-4785,2014.

Ryu „Kwangsun ., Oyama , Koh-Ichiro., Bankov Ludmil., Chen , Chia-Hung., Devi , Minakshi., Liu, Huixin, Liu, Jann-Yenq ., Precursory enhancement of EIA in the morning sector Contribution from midlatitude large earthquakes in the north-east Asian region., Advances in Space Research .,57 , 268-280 , 2016.

Ruzhin Yu.Ya., Depueva A.K., Seismoprecursors in space as plasma and wave anomalies. Journal of Atmospheric Electricity, 16, N. 3, 271-288. 1996.

Smirnov V.M.., Smirnova, E.V ; Ruzhin, Yu. Ya., Tynyankin S.I. and Skobelkin V.N. Complex Hardwaresoftware system for monitoring, detection and analysis of artificial and natural disturbances in the 
International Journal of Electronics and Applied Research (IJEAR) Vol. 2, issue 2, December 2015

Published Online (http://eses.co.in/ESES Journal)

ISSN 2395-0064

ionosphere, International Journal of Electronics and applied Research (IJEAR) ,ISSN 23950064,2 , 1-13 2015.

Sorokin, V., Hayakawa, M., Generation of Seismic-Related DC electric fields and Lithosphere-AtmosphereIonosphere coupling. Modern Applied Science, ISSN 1913-1844 (Print) ISSN 1913-1852, 7 (6)., 2013. 